\title{
DISIPLIN ROHANI SEBAGAI PRAKTEK IBADAH PRIBADI
}

\author{
Alfius Areng Mutak
}

\begin{abstract}
Abstrak: Istilah Disiplin Rohani sudah dikenal luas di kalangan orangorang percaya, walaupun ada yang tidak setuju dengan kata "disiplin" yang dikaitkan dengan hal-hal rohani. Secara umum disiplin rohani dipahami sebagai praktek atau kegiatan yang dilakukan dalam rangka membangun relasi dan komunikasi dengan Tuhan secara pribadi. Untuk membangun hubungan yang baik dengan Tuhan diperlukan kedisiplinan bukan semau dan sesukanya. Hal ini di perkuat oleh Paulus dalam nasehatnya kepada Timotius dengan mengatakan "Latihlah dirimu beribadah" (1 Timotius 4:7c). Paulus mengingatkan Timotius agar terus melatih dirinya beribadah. Untuk melatih diri membutuhkan disiplin. Karena disiplin rohani adalah sarana dalam menumbuh kembangkan kesalehan hidup. Selain untuk membangun komunikasi yang intens dengan Tuhan dan Bapa kita, disiplin rohani juga adalah sebagai bagian dari ibadah pribadi, karena lewat disiplin rohani seseorang dapat sekaligus beribadah kepada Allah Tuhannya. Tulisan ini mengangkat bagian-bagian dari disiplin rohani yang pada hakekatnya adalah ibadah pribadi itu sendiri. Melalui disiplin rohani seseorang mendekatkan diri kepada Tuhan, berkomuniksai dengan datang di hadapan Allah, karena esensi dari pada ibadah itu adalah perjumpaan dengan Allah.
\end{abstract}

Kata-kata kunci: Disiplin rohani, ibadah pribadi

Abstract: Spiritual discipline is a well known term, the term has been widely used in the area of church life and ministry. Although the term has been known, however, some scholars has different view about the term itself. Some do not does not agree that the term "discipline" is used in relation spiritual matters. A side from the above different views on the term used, this writing, however, believe that spiritual discipline is the right term to describe the need to build a relationship with the God. It's needed either in a personal as well as common communion with the Lord. 
Therefore, this writing, then will show the relationship between spiritual discipline and personal worship, which will come to the conclusion that spiritual discipline is a part of personal worship.

Key words: Spiritual discipline, personal worship, godliness

\section{PENDAHULUAN}

Disiplin rohani adalah sebuah istilah yang sangat umum karena banyak dibicarakan dalam konteks pembinaan dan pengembangan pelayanan gereja. Walaupun istilah ini sudah sangat umum tetapi disiplin rohani telah menimbulkan pandangan yang berbeda di kalangan pakar disiplin rohani. Dalam bukunya, Flora Slosson Wuellner mengatakan bahwa ia tidak terlalu senang menggunakan istilah "disiplin" untuk hal-hal rohani. Karena menurut Wuellner, kata disiplin memberikan konotasi rutin dan mekanis yang tidak sesuai untuk hal-hal spiritualitas. ${ }^{1}$

Terlepas dari apakah istilah spiritual rohani tepat atau tidak untuk hal-hal yang berkaitan dengan kehidupan rohani, penulis menyakini bahwa istilah disiplin rohani bukan semata-mata mengacu pada tindakan yang bersifat mekanis atau rutinitasnya, tetapi lebih mengacu pada kedisiplinan dalam membangun relasi dengan Tuhan yang tidak harus dibatasi oleh ruang atau waktu.

Dalam rangka membangun relasi dengan Tuhan itulah disiplin rohani diperlukan baik secara pribadi maupun komunal. Dalam kaitannya dengan ibadah, disiplin rohani menjadi penting dalam kaitannya dengan ibadah pribadi. Oleh karena itu tulisan ini membahas tentang disiplin rohani sebagai praktek dari ibadah pribadi (personal worship).

Flora Slosson Wuellner. Gembalakanlah Gembala-Gembala-Ku: Penyembuhan dan Pembaharuan Spiritual bagi Para Pemimpin Kristen. (Jakarta: BPK Gunung Mulia 2015), h.190. 
Karena topik ini mengandung dua variabel, maka tulisan ini akan membahas kedua variabel di atas dengan sistematika sebagai berikut: Bagian pertama, membahas disiplin rohani dari segi makna dan pentingnya membangun disiplin rohani yang baik. Pada bagian kedua, membahas tentang ibadah secara khusus ibadah pribadi. Kemudian pada bagian akhir membahas kedua variabel sebagai satu kesatuan untuk melihat bahwa disiplin rohani adalah sebagai praktek dari ibadah pribadi (personal worship) di hadapan Tuhan.

\section{DISIPLIN ROHANI}

Acara talk show di salah satu saluran televisi terkenal beberapa waktu yang lalu mengundang tiga atlet nasional sebagai bintang tamu untuk diwawancarai mengenai keberhasilan mereka menjadi juara dalam bidang olah raga yang selama ini mereka tekuni. Mereka adalah orangorang yang hari ini dikenal sebagai atlet nasional yang berhasil mengharumkan nama Indonesia baik di tingkat Asean maupun di tingkat dunia. Salah seorang atlet ketika ditanya apa yang menyebabkan ia bisa berhasil dalam bidang olah raga yang ia tekuni saat ini menjawab, bahwa keberhasilannya adalah karena kerja keras dan disiplin yang tinggi. Ada dua kata penting yang disebutkan oleh atlet tersebut tentang rahasia keberhasilannya yaitu kerja keras dan disiplin.

Kata disiplin tentu sudah sangat familiar di telinga banyak orang, karena sadar atau tidak sadar sejak kecil disiplin sudah menjadi bagian dari hidup manusia siapapun juga dia, tetapi, sampai di mana tingkat kesadaran untuk membangun disiplin yang tinggi menjadi persoalan lain. Disiplin adalah sebuah entitas yang luas, ia mencakup seluruh aspek kehidupan dan salah satunya adalah berkaitan dengan aspek kehidupan spiritualitas. Istilah yang sangat akrab dengan telinga kita hari ini ialah seseorang tidak akan mendapatkan apa-apa tanpa sebuah disiplin. Hal ini diungkapkan oleh R. Kent Hughes bahwa seseorang tidak akan pernah mendapatkan apa apa tanpa disiplin, khususnya dalam hal disiplin rohani. Hudges menulis: "We will never get anywhere in life without discipline, be it in the arts, business, athletics, or academics. This is doubly so in 
spiritual matters."2 Oleh sebab itu untuk mencapai kehidupan spiritual yang bertumbuh pada tingkatan tertentu di perlukan disiplin rohani.

\section{APA ITU DISIPLIN ROHANI}

Disiplin secara sederhana dapat diartikan sebagai latihan yang diharapkan dapat menghasilkan sifat atau karakter khusus dari sebuah pola perilaku. Kelli Mahoney dalam tulisannya tentang Spiritual Discipline melihat bahwa disiplin rohani itu sebagai sebuah latihan pikiran dan emosi untuk mendekatkan diri kepada Allah,

Spiritual disciplines exercise our spirit, mind, and emotions so that we become closer to God. They help us see His will for our lives more clearly so that we can live the life He desires for us. The more we practice these disciplines, the better we get at them, and the stronger we make our faith. ${ }^{3}$

Karena itu disiplin rohani dipahami sebagai upaya atau sarana untuk menumbuh kembangkan sifat karakter serta pola perilaku yang berkaitan dengan kerohanian yang menolong seseorang bertumbuh menuju kepada kedewasaan rohani. Dengan kata lain disiplin rohani adalah sarana untuk mengembangkan kerohanian seseorang yang telah mengalami perubahan oleh Kristus pada saat ia diselamatkan, yang lewat anugerah-Nya membebaskan orang percaya, yang telah mengalami pembaharuan seara holistik, yang diwujudnyatakan lewat perubahan dalam pikiran, perasaan, dan karakter yang secara bertahap menjadi nyata di dalam perilaku nyata. Ada banyak pendapat yang berkembang terkait dengan kapan disiplin rohani dimulai dan bagaimana proses pertumbuhan serta perkembangan rohani terjadi. Secara umum dipercaya bahwa disiplin rohani dimulai pada saat seseorang mengalami perjumpaan dengan Kristus, menerima Dia sebagai Tuhan dan juru selamatnya.

\footnotetext{
R. Kent. Hughes, Disciplines of a Godly Man. (Wheaton: Crossway, 2001), p.13

Kelli. Mahoney, Spiritual Discipline:Worship. Dalam http://christianteens.about.com/ od/christianliving/a/Spiritual-Discipline-Worship.htm (diakses 20 Januari 2016).
} 
Lalu apa dan mengapa disiplin rohani itu diperlukan dalam hidup orang percaya? Donald Whitney mengatakan bahwa disiplin rohani itu adalah sebagai cara atau sarana untuk memperoleh anugerah, agar bertumbuh dalam kesalehan hidup. Whitney menulis: "God has given us spiritual disciplines as a means of receiving His grace and growing in Godliness, by them we place ourselves before God for Him to work in us." Lebih lanjut Whitney mengatakan bahwa disiplin rohani juga sebagai saluran transformasi Allah dalam hidup yang merubahkan. "The spiritual disciplines are also like channels of God's transforming grace... as we place ourselves in them to seek communion with Christ, His grace flows to us and we are changed." 5 Dallas Willard juga melihat bahwa disiplin rohani adalah sarana bagi anugerah, sedangkan latihan-latihan bagi kesalehan itu hanyalah aktivitas yang memampukan kita menerima hidup dan kuasa-Nya lebih banyak lagi. Willard menulis:

"The disciplines are then, the clearest sense, a means to that grace and also to those gifts. Spiritual disciplines, exercises unto godliness. Are only activities undertaken to make us capable of receiving more of his life and power without harm to ourselves or others. $" 6$

Pemahaman yang sama dikemukakan oleh Hudgest yang meyakini bahwa dalam disiplin rohani, anugerah merupakan bagian yang sangat penting dalam formasi spiritualitas, Hudgest menulis:

The proper grace-oriented practice of spiritual disciplines is an essential part of our formation, moving us from reliance on our own willpower to dependence on God's grace. Spiritual disciplines in themselves can do very little by way of spiritual change, but when we use them to place us in God's presence, God can do his loving, restorative work. ${ }^{7}$

4 Donald S, Whitney. Spiritual Disciplines For The Christian Life. (Colorado Springs:

Navpress. 1991). p.16.

5 Ibid.

6 Dallas Willard, The Spirit of the Disciplines: Understanding How God Changes Lives. (San Francisco: Harper \& Row, Publishers. 1988), p.34.

7 R Kent Hughes, Disciplines of Godly Man. Wheaton: Crossway, 1991. 
Tuhan Yesus sendiri memberikan contoh atau model dalam membangun disiplin rohani. Hal ini menjawab pertanyaan sejauh mana disiplin rohani itu penting dalam diri orang percaya. Whitney menulis: “ The Lord Jesus not only expects these deciplines of us, He modeled them for us. He applied His heart to discipline. He disciplined Himself for the purpose of Godliness. And we are going to be Christ like, we must lives as Christ lived." "Hal yang sama juga diungkapkan oleh Hudgest yang melihat bahwa kebiasaan, struktur, ritme, dan rutinitas disiplin rohani menolong seseorang untuk meneladani gaya hidup Tuhan Yesus. Hudgest mengatakan:

The disciplines provide the reutines, rythms, and structural habits that enable us to adopt Jesus overall lifestyle. The corporate disciplines of receiving form a foundation of cultivated spiritual receptivity and provide a means of our receiving the strengthening grace, care, and knowledge needed for living the Christian life. ${ }^{9}$

Donald Whitney pada bagian lain menyatakan bahwa disiplin rohani adalah upaya yang dilakukan dalam rangka menumbuh kembangkan kehidupan rohani. Whitney menulis: "The spiritual disciplines are those personal and corporate disciplines that promote spiritual growth. They are the habits of devotion and experiential Christianity that have been practiced by the people of God since biblical times. "10 Lebih lanjut Whitney memberikan beberapa bentuk disiplin rohani sebagai berikut: merenungkan Firman, berdoa, ibadah, penginjilan, pelayanan, penatalayanan, puasa, keheningan, jurnal dan belajar. ${ }^{11}$ Karena itu disiplin rohani adalah cara atau sarana dalam rangka menumbuhkembangkan kesalehan hidup. Richard Foster mengatakan demikian: "A spiritual disciplines is an intentional directed action by which we do what we do in order to receive from God the ability (or

8 Donald. S, Whitney. Spiritual Disciplines For The Christian Life. (Colorado Springs:

Navpress. 1991), p. 18.

9 R. Kent Hughes, Disciplines of Godly Man, p. 93.

10 Whitney, Spiritual Disciplines For The Christian Life, p. 15.

11 Ibid. 
power) to do what we cannot do by direct effort. That's why the disciplines must become priority for us if we will be Godly." 12

Kesalehan hidup menjadi penting bagi orang percaya karena mau tidak mau harus diakui bahwa anak-anak Tuhan haruslah hidup saleh, sebagaimana dikatakan oleh Whitney "Godly people are disipilined people." 13

\section{DASAR ALKITAB}

"Latihlah dirimu beribadah. Latihan badani terbatas gunanya, tetapi ibadah itu berguna dalam segala hal, karena mengandung janji, baik untuk hidup ini maupun untuk hidup yang akan datang." (1 Timotius $4: 7 \mathrm{c}-8)$

Untuk memahami betapa pentingnya disiplin rohani dalam pertumbuhan iman dan kesalehan hidup, dapat dilihat dari elaborasi terhadap frasa penting di bawah ini. Alkitab terjemahan bahasa Indonesia (LAI) menuliskan: "Latihlah dirimu beribadah..." sedangkan the New Internasional Version (NIV) menerjemahkannya dengan katakata "Train yourself to be godly" dan The New American Standard Bible (NASB) dengan frasa "Discipline yourself for the purpose of godliness." Dari ketiga versi Alkitab di atas dijumpai paling tidak ada tiga kata yang berbeda tetapi memiliki arti yang sama. Yaitu kata "Latihlah." Berbentuk imperative/perintah agar berlatih. NIV disini menggunakan kata "Train." Yang berarti latihan, atau "latihlah" juga dalam bentuk imperative, yang memiliki arti yang sama dengan terjemahan bahasa Indonesia "latihlah"... sedangkan NASB menggunakan kata "discipline." Pada dasar ketiga kata di atas yaitu latihan, train, dan discipline adalah kata yang memilik makna yang sama. R. Kent Hudges menulis: "The word "train" comes from the word "gumnos", which means "naked" and is the word from which we derive our English word gymnasium. In traditional Greek athletic contest,

\footnotetext{
12 Richard Foster, Life With God: Reading Bible for Spiritual Transformation. (New York: HaperOne, 2008), p. 16.

13 Foster, Life With God, p. 15.
} 
...while in the New Testament it referred to exercise and training in general ."14 Dalam kaitan dengan topik ini digunakan kata "disiplin."

Kata disiplin dalam teks asli kitab suci Perjanjian Baru menggunakan kata "gumnasia" dari mana kata dalam bahasa Inggris gymnasium dan gymnastic berasal. Kata "gumnasium" berarti melatih atau mendisiplinkan. Alkitab versi King James menerjemahkan kata ini dengan "exercise" (latihan/melatih) yang mengacu pada latihan fisik/ disiplin yang baik dalam rangka memupuk atau membangun kekuatan dan kesegaran baru. Sadar atau tidak fakta menunjukkan bahwa tidak ada yang sesuatu yang bisa dicapai tanpa kedisiplinan. Tidak sedikit olahragawan terkenal yang kariernya berakhir tragis karena tidak mampu mendisiplinkan diri dengan baik. Dalam konteks arak-arakan iman, latihan rohani adalah dalam upaya untuk mengembangkan kesalehan. Kepada anak rohaninya Timotius, Paulus mengingatkan bahwa sebagai pemimpin rohani ia harus membangun hidup rohani yang lebih baik dengan terus melatih diri dengan kedisiplinan rohani yang tinggi.

Menarik untuk diperhatikan bahwa Rasul Paulus berbicara tentang pentingnya latihan/disiplin rohani ini berkaitan dengan ibadah. Hal ini dapat dilihat dari frasa berikutnya berbunyi: "Latihlah dirimu beribadah." (1Timotius 4:7). Alkitab bahasa Inggris The New Internasional Version (NIV) menerjemahkan dengan frasa: "Train yourself to be godly (Latihlah dirimu untuk menjadi saleh)". Ada dua kata yang kelihatannya berbeda di sini yaitu kata "beribadah" dan kata "saleh." Beribadah pada satu sisi adalah berkaitan dengan upaya yang dilakukan dalam rangka membangun relasi dengan Allah dalam bentuk penyembahan. Sedangkan saleh adalah mengacu pada hidup yang benar dan kudus, yang terkait dengan sumbernya. Pada hakekatnya kedua kata itu merupakan satu kesatuan yang mengacu pada pemahaman yang utuh tentang tujuan dari sebuah latihan rohani yaitu menuju kepada kesalehan hidup. Karena pada dasarnya disiplin rohani adalah dalam rangka membangun hidup yang saleh, hal ini di tegaskan oleh Whitney, ia mengatakan: "I will maintain that the only road to Christian maturity and godliness ... passes through

14 R. Kent, Hughes. Disciplines of a Godly Man, p.14. 
the practice of the spiritual disciplines... and I will emphasize that godliness is the goal of the disciplines." 15

Hal ini bersesuaian dengan ungkapan lanjutan yang ada dalam ayat 8 dengan mengatakan bahwa ibadah itu bermanfaat besar....ibadah itu berguna dalam segala hal ... karena mengandung janji baik untuk masa kini maupun untuk hidup yang akan datang (8). Ingat Paulus katakan bahwa latihan atau disiplin rohani itu bermanfaat besar, artinya latihan rohani itu berdaya guna dalam membangun relasi dengan Tuhan menuju kepada pertumbuhan rohani. Yang lebih menarik lagi ialah bahwa ternyata melatih/mendisiplinkan diri dalam ibadah itu mengandung janji, dan itu dapat dirasakan dan dialami saat ini, dan nanti di masa yang akan datang. Apakah janji itu? Janji menikmati indahnya berelasi dan bersekutu dengan Tuhan setiap saat, serta jaminan untuk menikmati bersama Tuhan dan kedekatan, kesukacitaan dan keindahan bersama dengan Tuhan selama-lamanya.

Ada banyak jenis dan praktek disiplin rohani yang dikembangkan oleh pakar. J. Wilhoit umpamanya, menyakini bahwa Tuhan Yesus memberikan tiga disiplin rohani yang dapat menolong pertumbuhan percaya Wilhoit mengatakan: "spiritual disciplines are Jesus- endorsed spiritual practices, (e.g., solitude, fasting, and meditation) that foster positive spiritual change and enable us to become the kind of people who genuinely desire to carry out his commands. "16 Tulisan ini membahas empat disiplin rohani yang terkait dengan ibadah pribadi, yaitu disiplin bermeditasi, disiplin berdoa, disiplin berpuasa dan disiplin keheningan.

15 Donald. S, Whitney. Spiritual Disciplines For The Christian Life. (Colorado Springs: Navpress. 1991), p.15.

16 James C, Wilhoit, Spiritual Formation as if the Church Mattered: Growing in Christ through Community. Grand Rapids: Baker Academic 2008), p.39. 


\section{EMPAT DISIPLIN ROHANI}

\section{Disiplin Bermeditasi}

Dalam perspektif iman Kristen, meditasi telah dipraktekkan dan bahkan dikembangkan sejak lama. Meditasi adalah sebuah praktek yang dilakukan oleh anak-anak Tuhan dalam Perjanjian Lama untuk mendengarkan Allah, serta upaya untuk berkomunikasi dengan Allah sang pencipta langit dan bumi, serta mengalami kasih dari Dia yang mengasihi Dunia ini. ${ }^{17}$ Hal ini dapat dilhat dari orang orang yang hidupnya dekat dengan Allah seperti Musa dalam Mazmur 63:7 berkata: "Apabila aku ingat kepada-Mu di tempat tidurku, merenungkan Engkau sepanjang kawal malam." Dalam Mazmur ini Musa menyatakan bahwa ia merenungkan Tuhan sepanjang malam, ia yang selalu mengingat-ingat serta menenangkan diri di tempat tidurnya memikirkan dan merenungkan Tuhan. Itu adalah bentuk dari meditasinya di hadapan Allah Tuhannya.

Pemazmur menyatakan bahwa meditasi yang ia lakukan pada waktu malam sebelum para penjaga terbangun, ia sudah bangun dan merenungkan janji-janji Tuhan. "Aku bangun mendahului waktu jaga malam untuk merenungkan janji-Mu.” (Mazmur 119:148). Menghadap hadirat Tuhan melalui perenungannya terhadap firman dan janji-janji Tuhan. Karena itu tepat sekali apa yang dikatakan oleh Richard Foster tentang meditasi Kiristen sebagai berikut: "Meditasi Kristen membawa kita kepada keutuhan batin yang perlu agar kita dapat memberi diri dengan leluasa kepada Tuhan, dan juga kepada persepsi rohani." ${ }^{18}$ Karena dengan bermeditasi mengarahkan seseorang untuk memasuki hadirat Allah yang hidup, dan menjadi momen di mana ia mendengar Allah berbicara dan terus menerus berbicara kepadanya. Teladan bermeditasi ditunjukkan oleh Tuhan Yesus, sebagaimana dikatakan oleh Hudgest: Jesus was consistently taking time a part to pray and commune with his

\footnotetext{
${ }^{17}$ Richard, Foster. Tertib Rohani, Sudahkan Anda Menapakinya? Terj. (Malang: Penerbit Gandum Mas, 2005), h. 29. Ibid., 31.
} 
father at table set for him in a solitary place after a day of intense ministry. ",19

\section{Disiplin Berdoa}

Doa menjadi bagian yang esensial dalam kehidupan manusia yang percaya. Berdasarkan Kamus Bahasa Indonesia, doa adalah permohonan, permintaan, pujian kepada Tuhan. Sedangkan berdoa artinya adalah menaikkan doa kepada Tuhan, sehingga doa dapat di artikan sebagai suatu permohonan yang ditujukan kepada Allah. Selain sebagai permohonan, doa juga adalah bagian dari persekutuan antara orang percaya dengan Tuhan dan Allahnya. Oleh karena itu dapat dikatakan bahwa doa adalah sebuah relasi antara manusia dengan Allah yang di dalamnya manusia berkomunikasi, memohon, meminta, memuji dan mengakui keberadaan Allah yang transendental.

Dalam perspektif kitab suci paling tidak ada empat unsur utama dari doa yang harus dipahami dengan baik. Keempat unsur itu adalah: a) Di dalam doa terkandung unsur pujian kepada Allah - Mazmur 95:6. b) Di dalam doa ada unsur pengakuan dosa - Mazmur 32:5. c) Di dalam doa ada unsur pengucapan syukur kepada Allah atas berkat-berkat dan pertolongan-Nya - Filipi 4:6. d) Di dalam doa ada unsur permintaan permohonan -1 Timotius 2:1. Doa adalah membangun relasi dan komunikasi antara diri orang percaya yang/dengan membuka dirinya di hadapan Allahnya. Melalui doa orang percaya bergaul, berelasi dengan kerendahan hati, bersyukur, dan meminta atau memohon kepada Tuhan Allah yang Mahakuasa ${ }^{20}$

Pemazmur adalah salah satu tokoh dari Perjanjian Lama yang mengekpresikan kerinduan yang mendalam serta kehausannya untuk berkomunikasi, berelasi, dan bergaul dengan Tuhan lewat doa yang ia

\footnotetext{
R. Kent, Hughes. Disciplines of a Godly Man, p.93.

20 Siahaan, Joshua. Definisi, Arti Dan Makna Doa Serta Mempersiapkan Doa dalam http://buletin-narhasem.blogspot.co.id/2009/12/artikel-definisi-arti-dan-maknadoa.html (diakses 11 Febuari 2016).
} 
ekspresikan dalam upaya mencari Tuhan dan hadirat-Nya. Dengan berkata: "Ya Allah, engkaulah Allahku, aku mencari Engkau, jiwaku haus kepada-Mu, tubuhku rindu kepada-Mu, seperti tanah yang kering dan tandus, tiada berair." (Mazmur 63:2). Hal yang sama yang dituliskan oleh penginjil Markus menyangkut tentang kebiasaan Yesus yang menyediakan waktu di awal hari untuk berada di suatu tempat untuk berkomunikasi, dan bergaul dengan Bapa-Nya dalam doa, " Pagi-pagi benar, waktu hari masih gelap, Ia bangun dan pergi keluar. Ia pergi ke tempat yang sunyi dan berdoa di sana." (Markus 1:35).

Semua orang yang telah bergaul dengan Allah telah menganggap doa sebagai urusan yang utama dalam kehidupan mereka. Hal itu dapat dilihat di dalam sejarah kekristenan, di sana dijumpai manusia Allah yang Tuhan pakai dengan luar biasa dalam pelayanan mereka telah memberikan teladan yang luar biasa tentang pentingnya doa dalam kehidupan pribadi maupun pelayanan mereka. Martin Luther reformator yang dipakai Tuhan di zamannya, di tengah-tengah kesibukannya yang luar biasa ia menyadari pentingnya berdoa. Dalam tulisannya sebagaimana yang dikutip oleh R. Foster ia mengatakan: "Urusan saya begitu banyak sehingga setiap hari saya harus berdoa selama 3 jam. "21

John Wesley berkata: "Allah tidak melakukan apa-apa kecuali sebagai jawaban atas doa". Pernyataannya dijawab dengan berdoa 2 jam setiap hari. Mengapa doa itu menjadi penting karena doa membawa kita ke garis depan kehidupan rohani. William Carey sebagaimana dikutip R. Foster mengatakan, " Doa- doa yang rahasia, yang sungguh-sungguh, dan penuh percaya - adalah sumber semua kesalehan pribadi. ${ }^{22}$ Oleh karena itu di sini terlihat jelas betapa pentingnya disiplin berdoa dalam kehidupan orang percaya, karena dengan semakin disiplin doa dikembangkan maka, "Semakin dekat kita dengan hati Allah, semakin kita melihat kebutuhan kita dan dan semakin kita menginginkan untuk menjadi seperti Kristus." 23

\footnotetext{
Foster. Tertib Rohani Sudahkan Anda Menapakinya?, p.55.

Ibid., p.54-56.

Ibid.
} 


\section{Disiplin Berpuasa}

Berpuasa berarti menahan diri dari makan, serta memfokuskan diri pada Tuhan, atau dengan kata lain puasa adalah upaya menahan diri atau berpantangan makan dengan maksud yang rohani, karena menurut $\mathrm{R}$. Foster berpuasa di dalam Alkitab selalu berpusat pada tujuan-tujuan rohani. $^{24}$ Walaupun di dalam Alkitab, berpuasa yang normal ialah berpantang dari semua makanan padat maupun cair, tetapi bukan berpantang air. Dari sana dikenal ada dua macam puasa yang dikenal dalam Alkitab yaitu "puasa penuh" dan "puasa sebagian." Puasa penuh ialah puasa tanpa makan dan minum. Ini terlihat dari puasa yang diperintahkan Ester kepada Mordekhai (Ester 4:16). Dan puasa sebagian ialah puasa yang tidak berpantang sepenuhnya. Ini nyata dalam kasus Yesus, yang oleh beberapa ahli disebutkan bahwa menjelang akhir puasa "Ia (Yesus) lapar". Menurut beberapa ahli hal ini menunjukkan bahwa dalam berpuasa Yesus berpantang makanan dan bukan air (Lukas 4:2).

Sebagaimana ibadah, puasa juga terdiri dari dua macam yaitu puasa umum (corporate fasting) dan puasa individu/perorangan (personal fasting). Yang dapat dilihat dari puasa yang diperintahkan Ester kepada Mordekhai adalah puasa umum yang melibatkan seluruh bangsa Yahudi pada saat itu, sedangkan puasa individu/ personal adalah puasa yang dilakukan oleh Yesus. Harus diingat bahwa tujuan berpuasa bukan hanya sekedar menahan diri atau berpantang terhadap makan maupun minuman. Tetapi yang perlu selalu di ingat ialah bahwa berpuasa itu harus selalu berpusat pada Allah. ${ }^{25}$ Hal ini sejalan dengan apa yang dikatakan oleh John Wesley sebagaimana dikutip oleh R Foster : "Pertama, biarlah puasa dilakukan bagi Allah dengan mata kita tertuju kepada Dia saja. Biarlah tujuan kita berpuasa itu hanya satu, dan satu ini saja yaitu memuliakan Bapa kita yang ada di sorga." 26

Sebagai sebuah disiplin rohani, disiplin puasa akan menolong bukan hanya sekedar belajar untuk menguasai atau mengotrol nafsu dan

\footnotetext{
24 Foster. Tertib Rohani Sudahkan Anda Menapakinya?, p.75.

25 Ibid., h.83.

26 Ibid., h.85.
} 
keinginan makan dan minum, tetapi disiplin puasa menolong untuk belajar menahan diri dari hal-hal yang bersifat keinginan diri manusia, dalam kaitannya dengan hawa nafsu yang tanpa kendali. Serta bagaimana dapat menahan dan menolak semua keinginan itu dan berfokus pada Tuhan Allah.

\section{Disiplin Keheningan}

Disiplin keheningan secara sederhana dapat diartikan sebagai menahan diri dari berbicara untuk sementara waktu guna mencapai tujuan rohani. Hal senada diungkapkan Whitney dengan mengatakan: The discipline of silence is the voluntary and temporarily abstention from speaking so that certain spirititual goals might be sought."27 Keheningan di sini mengacu pada situasi di mana seseorang berhenti berbicara sejenak, untuk menenangkan diri dan mendengar dari hati yang terdalam baik suara dirinya sendiri maupun suara Tuhan, lewat dialog internal yang terjadi dalam diri seseorang dan dialog dengan Tuhan.

Dengan kata lain keheningan itu mengarah pada saat sesorang berada dalam keadaan tenang tanpa gangguan apapun untuk bersama dengan Tuhan mendengar Tuhan berbicara secara pribadi, yang oleh Whitney disebut " just to be alone with God."28 Tuhan Yesus telah memberikan contoh tentang pentingnya momen bersama Bapa yang Ia lakukan masa hidup dan pelayanan-Nya di dunia ini. Di dalam Matius 14:23 dikatakan " Setelah Yesus mendengar berita itu, menyingkirlah Ia dari situ, dan hendak mengasingkan diri dengan perahu ke tempat yang sunyi." Walaupun dalam konteks perikop ini Yesus pada akhirnya harus mengajar dan memberi makan lima ribu orang. Frasa " Yesus menyingkir dari dan hendak mengasingkan diri ...ke tempat sunyi." Mengindikasikan bahwa di tengah-tengah kesibukan-Nya yang tinggi Yesus masih menyempatkan diri untuk mengasingkan diri ke tempat sunyi untuk bersama dengan Bapa. Dalam bagian Injil yang lain mencatat bahwa Yesus juga melakukan hal yang sama Ia pergi tempat yang sunyi . Dalam Injil Lukas 4:42 dikatakan " Ketika hari siang, Yesus berangkat dan pergi

27 Donald. S, Whitney. Spiritual Disciplines For The Christian Life, p.176.

28 Ibid. 
ke suatu tempat yang sunyi..." Dari catatan Injil di atas dapat disimpulkan bahwa pergi mengasingkan diri ke tempat yang sunyi adalah merupakan kebiasaan yang dilakukan Yesus setelah melayani dan mengajar banyak orang tentang kerajaan Allah, Tuhan Yesus selalu menyediakan waktu bersama dengan Bapa.

Keteladanan Yesus yang menyediakan waktu dengan mengasingkan diri untuk berdamai dengan Bapa dalam keheningan harusnya menjadi teladan dalam membangun disiplin keheningan sebagaimana ditulis oleh Whitney: “...to be like Jesus we must disiplin ourselves to find times of silence and solitude. Then we can find spiritual strength through these discipline, as Jesus did." ${ }^{, 29}$ Karena itu terkait dengan kepentingan menyediakan waktu dan tempat yang sunyi dalam keadaan sendiri dan dalam keheningan untuk mendengar suara Tuhan, whitney menyatakan: "Wherever it is, we need to find a place to be alone to hear the voice of Him whose presence is unseen yet more real than any other. ${ }^{30}$

\section{IBADAH}

Secara etimologis kata ibadah berasal dari kata dasar bahasa Ibrani "abad" (avad), yang berarti 'mengabdi'. Dari sudut makna/ isinya, maksud kata 'ABODAH' dalam Perjanjian Lama selalu mengacu pada penyembahan di dalam bait Allah yang merupakan titik pusat ibadah dalam arti umum, yaitu ketaatan pada perintah-perintah Tuhan dan pengabdian kepada-Nya. Dalam bahasa Yunani digunakan kata letherea yang berarti 'pengabdian', yang selalu dipakai dalam hubungan dengan "ibadah' (penyembahan). A. W. Tozer, seperti yang dikutip dalam D. J. Fant, A.W. Tozer dalam Christian Publications, mengartikan ibadah itu sebagai upaya merasakan, serta ekpresi rasa hormat dan kekaguman kita di hadapan Allah Bapa kita yang ada di surga. Tozer mengatakan:

"Worship is to feel in your heart and express in some appropriate manner a humbling but delightful sense of admiring awe and astonished wonder and overpowering love in the presence of that

29 Whitney. Spiritual Disciplines For The Christian Life, p.177.
30 Ibid. 
most ancient Mystery, that Majesty which philosophers call the First Cause, but which we call Our Father Which Are in Heaven. "31

Dallas Willard dengan jelas mengatakan bahwa ibadah itu bukan hanya sekedar memuji dan membesarkan nama Tuhan, tetapi jauh lebih dari itu ibadah adalah sebuah perayaan kebesaran dan kasih setia Tuhan, Willard menulis,

"The study of God in his Word and his works opens the way for the disciplines of worship and celebration. In worship we engage ourselves with, dwell upon, and express the greatness, beauty, and goodness of God through thought and use of words, rituals, and symbols. We do this alone as well as in union with God's people. To worship is to see God as worthy, to ascribe great worth to him. If in worship we are met by God himself, our thoughts and words turned to perception and experience of God, who is then really present in us in some degree of his greatness, beauty, and goodness. This will make for an immediate, dramatic change in our lives. ",32

Ibadah pada dasarnya adalah perjumpaan dengan Allah baik secara langsung maupun secara tidak langsung. Pengalaman Yesaya memberikan gambaran tentang perjumpaan dengan Allah dalam sebuah penglihatan (Yesaya 6:1-3). Steward sebagaimana yang dikutip oleh Laura Jonker mengatakan bahwa ibadah bertujuan untuk mengalami Tuhan yang hadir dalam ibadah. Laura Jonker menulis sebagai berikut,

"The intent of worship is to experience and praise God. In worship the primary mode of knowing God is by participation....the experience of God is one of mystery, awe, and wonder. An educational approach usually attempts to stand outside to explain and interprate mystery, while worship allows us to enter the

31 A. W. Tozer, in D. J. Fant, A. W. Tozer, Christian Publications, 1964, p.90. Lives. (San Francisco: Harper \& Row, Publishers. 1988), p.177. 
experience and dwell in the presence of God as a way of knowing. "33

Terkait dengan relasi antara disiplin rohani dengan ibadah, Wilhoit mengatakan, "Worship is the primary corporate spiritual discipline of the church, the discipline aspect of "worship" is to actually make it worship. ، 34

Elass Mateen pada bagian lain mengatakan bahwa ibadah itu sebagai disiplin rohani dapat dilakukan di mana saja sebagai ibadah umum maupun ibadah pribadi. Ellas Mateen menulis sebagai berikut,

"Indeed we are created with worship of God as the central mandate of our lives. As a spiritual discipline, worship can be exercised at any time, and has both corporate and individual aspects. Regular time alone before God the divine throne reminds us that we belong utterly to God, who deserves our full attention and allegiance. Regular time together with God's people in worship reminds us that God's purposes are much larger than our individual lives, that He is God over all existence and our small part in the great drama of creation must fit within the grand design of our heavenly father. Further, the discipline of cooperate worship enables us to see the glory of god more fully than our private times allow. No one individual exercises all the gifts are fully displayed, the character and activities of God are richly enjoyed through the spirit inspired ministries of fellow brothers and sisters. Worship deepens our humility by teaching us dependence on God and on one another in his name. ",35

\section{IBADAH PRIBADI}

A.W. Tozer membagi ibadah dalam dua bagian, yaitu apa yang disebut sebagai ibadah umum (corporate worship) dan ibadah pribadi (personal worship). Tozer mengatakan: "Worship is not only something

33 Laura. Jonker. "Experiencing God: The History and Philosophy of Children and Worship.” Christian Education Jurnal. Series .3. Vol. 12, p.305.

34 James C, Wilhoit, Spiritual Formation as if the Church Mattered: Growing in Christ through Community, p. 40.

35 Elass, Mateen. Foundations of Christian Faith. https://books.geogle.co.id (diakses 20 Januari 2016). 
experienced when we come together in the church building. Individual worship should take place on a daily basis, rising from us to our Heavenly Father. "36 Pendapat yang sama juga dikemukakan oleh Phil Coleman yang mengatakan bahwa ibadah pribadi seharusnya mendahului ibadah umum. Coleman melihat bahwa ibadah pribadi itu bermuara dari ibadah umum, "Worship must first happen on the individual level before it can ever happen on the corporate worship level i.e., at church on the week end. Corporate worship is simply the overflow of our personal worship. "37

Tim Challies mengatakan bahwa ibadah pribadi ialah ibadah yang dilakukan secara individu. Karena itu Challies mengusulkan agar ibadah pribadi itu dilakukan dengan menjauhkan diri dari keramaian, anak-anak, sahabat maupun pasangan. Carilah tempat yang sunyi/tenang, dengan posisi yang tepat dan nyaman seperti berlutut, duduk, berbaring bahkan berjalan. Dengan susunan ibadah sebagai berikut, ${ }^{38}$

1. Menghampiri Bapa, melalui Yesus. Mulailah ibadah pribadi dengan mengakui bahwa hanya melalui Yesus Kristus Anda dapat menghampiri Allah Bapa. Lewat karya Kristus di atas kayu salib yang telah menebus Anda, seraya menyadari ketidakberdayaan Anda di hadapan-Nya (Efesus 2:18).

2. Pengagungan dan Pujian. Kekaguman terhadap kebesaran Tuhan seharusnya menghasilkan sukacita yang besar bagi anak Tuhan. Datanglah di hadapan-Nya dengan memuji dan memuliakan Allah, karena Dia lah Allah yang Agung dan maha mengasihi, kekal selama-lamanya. (Mazmur 37:4).

3. Pengakuan dosa (Memeriksa Diri dan Mengakui Dosa-Dosa). Dalam ibadah pribadi ada pertobatan pribadi, dengan mengakui segala kelemahan, dosa, dan cacat cela. Minta Allah mengampuni dosa-dosa itu, dengan meyakini bahwa Ia adalah setia yang akan mengampuni segala kesalahan dan dosa (1 Yohanes 1:9).

\footnotetext{
36 Tozer W. Tozer, quoted in D. J. Fant, A. W. Tozer, Christian Publications, 1964, p. 90

37 Tim Challies, Personal Worship dalam www.challies.com/personalreflections/personal-worship (diakses 12 Febuari 2016).

38 Tim Challies, Personal Worship dalam www.challies.com/personalreflections/personal-worship (diakses 12 Febuari 2016).
} 


\section{Masuk dalam Persekutuan (Mengungkapkan kerinduan untuk} bersekutu dengan Dia). Datang kehadapan-Nya dengan dengan segala kerendahan hati, serta ketidakberlayakan anda. Untuk memohon dari hati dan mengekspresikan kerinduan hati yang Anda yang terdalam untuk bersekutu dengan Dia dalam keintiman.(Mazmur 42:1-2).

5. Pembacaan Mazmur. Bacalah bagian dari kitab Mazmur, sedapatnya bacalah dengan bersuara, atau pembacaan dalam hati tanpa menggunakan suara.

6. Merenungkan Firman Tuhan. Pusatkan hati dan pikiran untuk membaca dan merenungkan Firman. Mulailah dengan memohon Roh Allah memberikan pencerahan agar Allah berbicara melalui Firman-Nya. Baca bagian dari Firman dengan meyakini bahwa Tuhan berbicara kepada Anda melalui Firman-Nya dan Anda sedang mendengar suara-Nya. Dalam suasana perenungan bacalah bagian atau ayat-ayat tertentu, mintalah hikmat dari Tuhan untuk mengerti dan merefleksikannya dalam kehidupan anda.

7. Bersyafaat. Bawalah dalam di hadapan Allah apa yang menjadi kebutuhan dan beban orang lain. Teman, keluarga, pemimpin gereja, pemerintah, yang mengalami musibah, fakir miskin, dan yang menderita sebagai korban perang.

8. Doa permohonan pribadi. Membawa permohonan pribadi di hadapan Tuhan, terkait dengan kerinduan dan beban hati Anda, memohon pimpinan, pemeliharaan, pembebasan, hikmat dan ketabahan dalam menghadapi berbagai tantang dan kesulitan yang Anda dan keluarga hadapi. Bawa semua permohonan Anda di hadapan-Nya dengan iman dan penuh kerendahan hati dengan keyakinan bahwa akan mendengar kerinduan hati Anda.

9. Mengucap Syukur. Doa ucapan syukur berisikan ungkapan hati yang mensyukuri anugerah keselamatan yang telah Anda terima, kasih setia Tuhan, pimpinan dan pemeliharaan-Nya yang begitu sempurna, dan bersyukurlah atas kesempatan Anda boleh bersama dengan Dia.

10. Menyerahkan hari ini kepada Tuhan. Serahkan kegiatan sepanjang hari ke dalam tangan Tuhan. Meminta pertolongan, 
kesabaran, bimbingan, himat, iman dan yang lainnya secara spesifik, agar Anda dapat melewati hari ini dengan penyertaan-Nya.

Tim Challis meyakini bahwa apabila urut-urutan ibadah pribadi ini dilakukan dengan baik akan sangat bermanfaat untuk membangun hubungan yang indah bersama Tuhan, Challies berkata, "If you have used this method, I trust you have just spent a meaningful, intimate hour with the Lord. May God bless you as you dedicate yourself to becoming intimate with Him." 39

\section{DISIPLIN ROHANI SEBAGAI IBADAH PRIBADI}

\section{Ibadah Dan Disiplin Doa}

Menurut J.G.S. Thomson berdoa merupakan ibadah yang mencakup sikap seseorang ketika ia mendekatkan dirinya kepada Tuhan. Orang Kristen dikatakan beribadah kepada Tuhan jika ia mengakui dan mengagungkan Allah, memuji serta memuliakan Nama-Nya serta menaikkan doa dan permohonan kepada-Nya. ${ }^{40}$ Dengan kata lain, doa adalah bagian penting dalam ibadah pribadi, karena di dalam doa orang percaya berinteraksi dengan Tuhan, serta kesempatan untuk merasakan anugerah dan pemeliharaan Tuhan dalam hidupnya. Hudgest memberikan contoh praktis berkaitan dengan kehidupan doa pribadinya,

"My personal prayer life has been greatly enhanced by corporate experiences prayer. My first sustained time of individual prayer was on a corporate prayer retreat, where we had prayed together as a group and then were given time to prayed, and the initiated me into a pattern of extended personal times of prayer. ",1

Walaupun Hudgest menekankan pentingnya doa dalam ibadah bersama dalam gereja, ia juga menekankan bahwa doa adalah juga merupakan bagian penting dalam ibadah pribadi. Oleh karena itu

\footnotetext{
39 Tim Challies, Personal Worship dalam www.challies.com/personalreflections/personal-worship (diakses 12 Febuari 2016).

40 Josua Siahaan, Buletin Narhasem. Edisi Juni 2009. Blogspot.com (diakses 11 Febuari 2016).

41 R. Kent Hughes, Disciplines of Godly Man. Wheaton: Crossway, p. 96.
} 
membangun disiplin doa itu menjadi suatu keharusan. Karena itu Hudgest lebih lanjut berkata, "A primary place where corporate prayer happens in the church is during our gatherings for worship. Here, through corporate prayers and through opportunities for quiet reflective prayers, people have the opportunity to pray and sees prayer modeled for them. ${ }^{42}$

\section{Ibadah Dan Disiplin Meditasi}

Disiplin meditasi adalah saat-saat di mana seseorang dibawa ke dalam sebuah perenungan di hadapan Tuhan, merenung dan merefleksikan Tuhan dalam segala kebesaran dan keagungan-Nya. Hal itu lebih nyata lagi terlihat dalam konteks ibadah pribadi di hadapan Tuhan. Richard Foster mengatakan bahwa, "Meditasi selalu merupakan bagian utama dari ibadah Kristen." ${ }^{43}$ Karena dengan bermeditasi dalam ibadah pribadi itu mengarahkan seseorang untuk memasuki hadirat Allah yang hidup, karena pada saat bermeditasi dalam ibadah pribadi seseorang memasuki suatu momen di mana ia mendengar Allah berbicara dan terus menerus berbicara kepadanya.

\section{Ibadah Dan Disiplin Keheningan}

Ibadah kepada Tuhan tidak selalu harus mengeluarkan kata-kata, bunyi atau gerakan serta tindakan-tindakan peragaan, namun ibadah juga diungkapkan dalam bentuk ketenangan dan keheningan. Whitney mengatakan, "The worship of God does not always require words, sounds, or actions. Sometimes worship consist of a God-focused stillness and hush",44 Hal ini diungkapkan secara jelas dalam kitab suci; Nabi Habakuk umpamanya menyerukan agar seluruh dunia berdiam diri dan hening ketika menghadap Allah dalam bait-Nya, "Tetapi TUHAN ada di dalam bait-Nya yang kudus. Berdiam dirilah di hadapan-Nya, ya segenap bumi." (Habakuk 2:20). Nabi Zefanya juga menyatakan hal yang sama tentang pentingnya berdiam diri di hadapan Allah, yang ia ungkapkan

\footnotetext{
42 Hughes, Disciplines of Godly Man. Wheaton: Crossway, p. 96.

43 Richard, Foster. Tertib Rohani Sudahkan Anda Menapakinya?, p. 28.

44 Donald S, Whitney. Spiritual Disciplines For The Christian Life, p.179.
} 
sebagai berikut: "Berdiam dirilah di hadapan Tuhan ALLAH..." (Zefanya 1:7). Walaupun perikop ini berbicara tentang hari penghakiman pada akhir zaman, Nabi Zefanya mengingatkan pentingnya berdiam diri ketika menghadap Allah, bahkan pada hari penghakiman sekalipun.

Berdiam diri/hening di hadapan Tuhan menjadi bagian yang sangat penting dalam menghadap Tuhan, baik itu dalam konteks ibadah umum maupun dalam konteks ibadah pribadi. Di mana seseorang dituntut untuk berdiam diri dengan tenang di hadapan Tuhan. Whitney menulis sebagai berikut, "Be silent before the sovereign LORD. It's not just a silence that's enjoined, but a silence "before him," before the Sovereigh Lord." That's silence of worship. There are time to speak to God, and there are times simply to behold and adore Him in silence. "45 Sedangkan tujuan dari menenangkan diri dalam keheningan di hadapan Tuhan adalah dalam rangka mendengar Tuhan berbicara dalam keheningan seperti diungkapkan oleh Whitney, "Of course, it isn't absolutely to get away from noices and people in order to hear God speak, otherwise we'd never perceive His promptings in the course of everyday life, or even in peopled worship servies. “ 46

\section{SIMPULAN}

Untuk mengakhiri pembahasan tentang disiplin rohani sebagai ibadah pribadi, tulisan Kelli Mahoney akan menolong untuk lebih memahami disiplin rohani dan ibadah pribadi dengan mengatakan demikian,

As we practice the spiritual discipline of worship, we learn to experience God in His Glory. We easily identify His works in our lives. We seek out our time with God in prayer or conversation. We never feel alone, because we always know God is right there with us. Worship is an ongoing experience and connection with God. ",77

\footnotetext{
45 Donald S, Whitney. Spiritual Disciplines For The Christian Life, p.179.

46 Whitney. Spiritual Disciplines For The Christian Life, p.178.

47 Kelli, Mahoney, Spiritual Discipline: Worship, http://christianteens.about.com/od/christianliving/a/Spiritual-Discipline-Worship.htm (diakses 20Januari 2016).
} 


\section{DAFTAR RUJUKAN}

................, Life With God: Reading Bible for Spiritual Transformation. New York: HaperOne, 2008.

Foster, Richard. Tertib Rohani Sudahkah Anda Menapakinya?. Terj. Malang: Penerbit Gandum Mas, 2005.

Hughes, R. Kent. Disciplines of Godly Man. Wheaton: Crossway, 1991.

Laura, Jonker. Christian Education Jurnal. Experiencing God : The History and Philosophy of Children and Worship. Series 3, Vol.12. No. 2.

Tozer, A. W. in D. J. Fant, A. W. Tozer. Christian Publications, 1964.

Whitney, Donald S. Whitney. Spiritual Disciplines For The Christian Life. Colorado Springs: Navpress, 1991.

Wilhoit, James C. Spiritual Formation as if the Church Mattered: Growing in Christ through Community. Grand Rapids: Baker Academic, 2008.

Willard, Dallas. The Spirit of the Disciplines: Understanding How God Changes Lives. San Francisco: Harper \& Row, Publishers, 1988.

Wuellner Flora.S. Gembalakanlah Gembala-Gembala-Ku: Penyembuhan dan Pembaharuan Spiritual bagi Para Pemimpin Kristen. Jakarta: BPK Gunung Mulia, 2015.

\section{SUMBER INTERNET}

Challies, Tim. Personal Worship dalam www.challies.com/personalreflections/personal-worship (diakses 12 Febuari 2016). 
24 Disiplin Rohani Sebagai Praktek Ibadah Pribadi

Mahoney, Kelli. Spiritual Discipline: Worship dalam http://christianteens.about.com/od/christianliving/a/SpiritualDiscipline-Worship.htm (diakses 20 Januari 2016).

Mateen, Elass. Foundations of Christian Faith dalam https://books.geogle.co.id (diakses 20 Januari 2016).

Siahaan, Joshua. Definisi, Arti Dan Makna Doa Serta Mempersiapkan Doa dalam http://buletin-narhasem.blogspot.co.id/2009/12/artikeldefinisi-arti-dan-makna-doa.html (diakses 11 Febuari 2016) 